\title{
Patients' and relatives' assessment of clozapine treatment
}

\author{
M. C. ANGERMEYER, ${ }^{1}$ W. LÖFFLER, P. MÜLLER, B. SCHULZE AND S. PRIEBE \\ From the Department of Psychiatry, University of Leipzig and Department of Psychiatry, \\ University of Göttingen, Germany; and Unit for Social and Community Psychiatry, St Bartholomew's \\ and the Royal London School of Medicine, London
}

\begin{abstract}
Background. Subjective evaluations by schizophrenic patients and their relatives of clozapine treatment were assessed as part of an exploratory study.

Methods. A problem-centred interview was carried out with 80 patients at discharge from in-patient or day-hospital treatment. Views of 46 relatives on the treatment were also assessed.

Results. In addition to expected effects (improvement of or stabilisation of one's state of mental health, antipsychotic effects), patients surprisingly often highlighted the calming and relaxing effect of clozapine as well as improved sleep as particularly positive. While more than half of the respondents expected a worsening of their condition if they stopped taking medication, only every fifth patient feared a relapse. Among the negative effects, fatigue and sedation were cited by far the most often. The absence of extrapyramidal side effects was clearly noted as an advantage of clozapine. Only $10 \%$ of those questioned were aware of the risks for the haemotopoetic system associated with the drug. Differences were found between patients' and relatives' assessments particularly with regard to the negative effects.

Conclusions. Patients and relatives frequently hold specific and distinct views on clozapine treatment. These views should be considered when patients and relatives are informed and when compliance is addressed.
\end{abstract}

\section{INTRODUCTION}

Since its introduction, clozapine has been studied in numerous clinical trials. Its efficacy, safety, cost-effectiveness and positive effect on quality of life are well documented (Fitton \& Head, 1990; Meltzer et al. 1990, 1993; Baldessarini \& Frankenburg, 1991; Breier et al. 1994; Wagstaff \& Bryson, 1995; Morris et al. 1998). While there is a substantial body of research on clozapine, these studies generally use standardized quantitative assessment instruments, aiming at an accurate and objective measurement of medication effects. However, their claim to objectivity overlooks that the statements of the patients,

${ }^{1}$ Address for correspondence: Dr Matthias C. Angermeyer, Department of Psychiatry, University of Leipzig, Johannisallee 20, 04317 Leipzig, Germany. which form to a large extent the basis of these clinical studies, are by no means objective, but subjectively influenced by reflecting the patients' preferences and attitudes (Retzow \& Emrich, 1998). To date, studies that focus explicitly on subjective assessments of psychotropic drug treatment have been the exception (Windgassen, 1989; Finn et al. 1990; Naber, 1995; Day et al. 1996; Angermeyer \& Matschinger, 2000). Therefore, the subjective view of those receiving the treatment, was the specific concern of the present study. We wanted to know what people suffering from schizophrenia thought about neuroleptic treatment, and especially how they perceived treatment with clozapine. What do they like about this medication? What is bad? In their opinion, what are the risks associated with this treatment? What would they expect to happen if they stopped taking their medication? In order 
to answer these and other questions, we carried out qualitative interviews with schizophrenic patients. For a subsample of patients, we also investigated their relatives' view on clozapine. From these statements, we subsequently hoped to find hints as to what aspects may be of importance for the patients' compliance with neuroleptic treatment.

\section{METHOD}

The study was carried out simultaneously at the Department of Psychiatry at the University of Göttingen and at the Lower-Saxon Regional Psychiatric Hospital in Göttingen, at the Psychiatric Hospital 'Philippshospital' in Riedstadt and at the Department of Social Psychiatry at the Free University Berlin. The four hospitals were chosen with the aim of including a wide spectrum of patients with regard to treatment setting (university hospital $v$. state hospital) and place of residence (urban $v$. rural). All schizophrenic patients (ICD-9, 295) between 18 and 60 years of age who had been treated with clozapine during their in-patient or acute day-hospital treatment and were discharged with the recommendation to continue this medication on an out-patient basis were included in the study. In total, 104 patients consecutively discharged from the four hospitals participated. At discharge from hospital, the 'Interview on Subjective Illness Theory' (Holzinger et al. 2001) was carried out with the patients.

The 'Interview on Subjective Illness Theory' is a problem-centred interview (Witzel, 1985). This form of interview is similar to the focused interview developed by Merton \& Kendall $(1945 / 46)$. The semi-structured interview is designed in such a way as to give respondents the opportunity to freely articulate their views, i.e. it is intended to bear the maximum possible resemblance to an open conversation. However, it focuses on a particular problem introduced and continuously probed for by the interviewer. An interview guide was developed specially for the interview, which addresses the essential aspects of subjective illness theory (labelling, causal attributions, perceptions of prognosis, control attributions). In connection with this, we also assessed respondents' views on the treatment they receive, including specific questions on clozapine treatment. We posed the following introductory question: 'You are taking Clozaril at the moment. How do you feel about it?'. Further questions were 'What, do you think, would change if you were to stop taking this medication?' and 'Do you think that taking Clozaril for longer periods of time could lead to problems of any sort?'. Finally, patients were asked to compare their current medication with the one they had received previously: 'Earlier you also took other medications. Is there any difference between Clozaril and the drugs you took before?'. The same questions, phrased slightly differently, were also posed to the relatives. Interviews took between 35 and $55 \mathrm{~min}$. They were tape-recorded and subsequently transcribed.

The full set of transcripts was analysed by means of structuring qualitative content analysis (Mayring, 1990). The method simultaneously allows the analysis of subjective concepts and the identification of structures in the qualitative material. It was designed to facilitate the combination of qualitative methods with statistical analysis. Hence, it was particularly suited for our study, which aimed at assessing both subjective evaluations and the frequency and distribution of the judgments made. In a first step, texts were divided into blocks based on units of meaning. Blocks were then given a code, which was formulated on the basis of the original formulations of the respondents (paraphrasing). Paraphrases subsequently served as the basis for the formation of categories, which was carried out by means of an inductive method, i.e. new categories were formed and constantly revised until all relevant information from the interview transcripts was included. Coding was done independently by two researchers. Results were compared by an interdisciplinary research team consisting of psychiatrists and psychologists. The team resolved possible discrepancies and summarized similar codes in generic categories until the final coding system was arrived at.

For content analysis, a computer-based approach was chosen, using the software package WinMax (Kuckartz, 1988). The program allows simultaneous access to the texts analysed, the coded blocks of text and the categories of the coding system relevant for the respective transcripts. It is further designed to facilitate the 'quantification' of verbal data by defining variables from the categories and reading them 
into a statistics package without losing reference to the original data. In our study, data collected through the inductive procedure was thus converted into an SPSS file for statistical analysis. Frequency counts were carried out for the number of mentions in each category. The McNemar test was used to analyse whether there were statistically significant differences between the patient's views of clozapine treatment and those of their relatives.

In total, analysable transcripts of the interview were available for 80 patients. Of the 104 patients originally recruited, 18 did not give their agreement with taping the interview. In six cases, the quality of the tape recording was too poor to allow transcription. Of the remaining 80 patients, $60 \%$ were male. One-third of the sample was: under 30 ; between 30 and 40 ; and over 40 years of age. Seventy-four per cent of the sample was single, $37.5 \%$ lived on their own, $20 \%$ lived with their parents and $17.5 \%$ with their spouses or partners. With regard to education: $32.5 \%$ of the respondents had completed secondary school below O-Levels; $32.5 \%$ had done O-Levels; and $26 \%$ had done ALevels. Among the sub-types of schizophrenia, the paranoid type (ICD-9, 295.3) was most frequently represented at $42.5 \%$. On average, patients had been admitted to in-patient treatment on five previous occasions. The median length of cumulative stay at the hospital was 15 months. At the time of the interview, patients displayed fewer positive symptoms and about as many negative symptoms as the representative sample of first admitted schizophrenic patients studied in the ABC project (Häfner et al. 1992). Before being switched to clozapine, patients had been treated with up to 13 different traditional neuroleptics (median $=4)$. On average, patients had been on clozapine for almost 3 years (Table 1).

At one site (Göttingen), 38 patients were questioned using the 'Interview on Subjective Illness Theory' and again 6 months after discharge. For 46 patients, we also investigated their closest relatives' attitude to clozapine treatment. Eighteen patients did not have close friends or relatives. In nine cases, patients objected against their relatives being interviewed, in seven cases the relatives declined to participate in the study. Forty-one per cent of the relatives questioned were parents (in most
Table 1. Clinical characteristics

\begin{tabular}{|c|c|c|c|}
\hline & $\%$ & Median & Range \\
\hline \multicolumn{4}{|l|}{ CATEGO syndrome } \\
\hline Nuclear syndromes & $51 \cdot 9$ & & \\
\hline Auditory hallucinations & $29 \cdot 6$ & & \\
\hline Delusions of persecution & $25 \cdot 9$ & & \\
\hline Delusions of reference & $27 \cdot 2$ & & \\
\hline Residual syndrome & $27 \cdot 2$ & & \\
\hline Affective flattening & $30 \cdot 9$ & & \\
\hline Slowness & $43 \cdot 2$ & & \\
\hline Lack of energy & $50 \cdot 6$ & & \\
\hline Simple depression & $76 \cdot 5$ & & \\
\hline Incoherent speech & $2 \cdot 5$ & & \\
\hline $\begin{array}{l}\text { Number of previous } \\
\text { hospital admissions }\end{array}$ & & 5 & $1-28$ \\
\hline $\begin{array}{l}\text { Duration of previous } \\
\text { hospital admissions (months) }\end{array}$ & & 15 & $1-143$ \\
\hline $\begin{array}{l}\text { Number of previously } \\
\text { prescribed neuroleptics }\end{array}$ & & 4 & $1-13$ \\
\hline $\begin{array}{l}\text { Length of time on clozapine } \\
\text { (months) }\end{array}$ & & 34 & $1-96$ \\
\hline
\end{tabular}

cases mothers), $20.8 \%$ were spouses or partners, $4.1 \%$ were the patients' brothers or sisters and $33.4 \%$ were other persons.

\section{RESULTS}

\section{Positive effects of clozapine treatment}

Most frequently - in almost one-third of the cases - patients generally stated that they felt better as a result of clozapine. The degree of improvement varied between 'a bit', 'increasingly' and 'considerably' (Table 2). For example one patient said: 'I mean, in retrospect, I feel better, so I guess it must have been the right treatment'. Patients felt helped by the medication and comparatively well. Some patients $(5 \%)$ spoke of a stabilization: 'I feel more stable now, not so weak anymore'. In only a few cases, patients mentioned that they were fully recovered thanks to the treatment: 'Now I feel just as well as I used to when I was healthy'. With striking frequency, a favourable influence of clozapine on sleeping patterns was emphasized. Twenty-five per cent of the respondents mentioned this beneficial effect. Clozapine would help patients to sleep: one could sleep 'well', 'calmly', 'deeply', and even 'fantastically'. One patient stated in this regard: 'Well, I would say, it's a bit of a sleeping pill, perhaps, 'cause I always sleep through the night'. Just as frequently, clozapine's calming 
Table 2. Assessment of clozapine treatment by

\begin{tabular}{|c|c|}
\hline & $\%$ \\
\hline \multicolumn{2}{|l|}{ Positive effects } \\
\hline Overall improvement & $30 \cdot 0$ \\
\hline Improved sleep & $27 \cdot 5$ \\
\hline Calming effect & $27 \cdot 5$ \\
\hline Antipsychotic effect & $18 \cdot 7$ \\
\hline Antidepressant effect & $11 \cdot 2$ \\
\hline Anxiolytic effect & $7 \cdot 5$ \\
\hline Improved functioning & $7 \cdot 5$ \\
\hline Recovery & $5 \cdot 0$ \\
\hline Stabilization & $5 \cdot 0$ \\
\hline Reduction of cognitive deficits & $5 \cdot 0$ \\
\hline Protection/distance & $3 \cdot 7$ \\
\hline No statement & $16 \cdot 2$ \\
\hline \multicolumn{2}{|l|}{ Negative effects } \\
\hline Fatigue/sedation & $56 \cdot 2$ \\
\hline Lack of motivation & $21 \cdot 2$ \\
\hline Hypersalivation & $21 \cdot 2$ \\
\hline Anticholinergic effects & $16 \cdot 2$ \\
\hline Weight gain & $15 \cdot 0$ \\
\hline Orthostatic hypotension & $11 \cdot 2$ \\
\hline Cognitive deficits & $11 \cdot 2$ \\
\hline Restlessness & $5 \cdot 0$ \\
\hline Increased perspiration & $5 \cdot 0$ \\
\hline Sexual dysfunction & $5 \cdot 0$ \\
\hline Akathisia & $3 \cdot 7$ \\
\hline Headaches & $3 \cdot 7$ \\
\hline Other & $12 \cdot 5$ \\
\hline No statement & $13 \cdot 7$ \\
\hline \multicolumn{2}{|c|}{ Comparison with traditional neuroleptics } \\
\hline No parkinsonism & $27 \cdot 5$ \\
\hline No akathisia & $12 \cdot 5$ \\
\hline No acute dystonia & $12 \cdot 5$ \\
\hline No restlessness & $11 \cdot 2$ \\
\hline Reduced sedation & $8 \cdot 7$ \\
\hline Reduced cognitive deficits & $3 \cdot 7$ \\
\hline Other & $16 \cdot 2$ \\
\hline No statement & $32 \cdot 5$ \\
\hline
\end{tabular}

effect was highlighted. Taking the drug, one would feel calmer, more relaxed, more balanced: 'Clozaril is also calming ... I mean there's a kind of substance in it... some sort of a salt or something... or some sort of substance, you know, that makes the nerves work more slowly ... or something ... Well, I'm not a doctor...' Another patient explained the calming effect as 'a blockage of brain functions'. When asking about the positive effects of clozapine, its antipsychotic effect was mentioned comparatively rarely. Among these statements, it was most frequently remarked that the drug caused the voices to become fainter, that the latter were only present in the evening or 'upon request', or that they had disappeared completely. One patient was very satisfied: 'I don't see a chance for the voices. Yes, this is the only drug that managed to get rid of the voices'. In addition, almost every tenth patient noticed an antidepressant effect. Clozapine was identified as leading to a brighter mood: 'When I'm rather down and then take these tablets... well, that helps me all right'. An anxiolytic effect was mentioned slightly less frequently: 'The anxieties are less present'. Some patients also stressed the positive influence on their ability to work and to successfully manage their daily lives. One patient ascribed to the medicine that 'I can spend 8 hours at the university without any problems ... I can go in for sports and things like that like everybody else... without any restrictions'. Another group of patients considered the medication as a protection from the illness. In accordance with the stress-vulnerability concept, one patient argued: 'And I've got the impression, that the stuff shields me...that it shields my soul... because I'm not very well protected, and this medicine, Clozaril, is more capable of giving my soul some protection'. A second patient also conveyed this effect: 'Therefore it does help ... well, because I don't experience these irritations as forcefully anymore ... 'cause I am a little shielded'.

\section{Expected consequences of a discontinuation of clozapine treatment}

A further aspect, which is revealing with regard to the evaluation of the positive effects of a drug, is the answer to the question as to what would happen if one stopped taking it. Almost half $(43.7 \%)$ of the respondents expected a worsening of their mental state in that case. Twenty per cent of those questioned expressed the fear they would 'become ill once again'. According to the patients' judgement, the "possibility of a relapse would be quite large'. For another patient it was certain that 'If I didn't take it, the psychosis would rule again'. One patient expressed that the reappearance of the psychosis would be 'a real catastrophe'. A further patient spoke from experience: 'When I leave that out, the skies fall upon me'. In view of the above-mentioned positive effects of clozapine on the quality of sleep it is not surprising that $10 \%$ of patients expected insomnia if they stopped taking the medication. Five per cent of those questioned feared they would become more restless, irritable and 'exited/nervous/flustered' again. The op- 
posite case, i.e. that some patients anticipated an improvement in their condition, was comparatively rare - only $7.5 \%$ anticipated such a development. For example, one patient believed that 'without medication, I am able to think better... clearer, able to work better, go out more in the evenings, go for walks'. Even less frequently (in $5 \%$ of the cases), patients believed that whether or not they take the psychotropic drug was irrelevant to their well-being. Thirtyfive per cent of the respondents were incapable of making a statement in this regard, $12.5 \%$ answered this question with 'I don't know'.

\section{Negative effects of treatment with clozapine}

While respondents on the one hand welcomed the calming effect of clozapine, they also complained about the sedating effect of the drug (Table 2). More than half of those questioned considered this to be a disadvantage of clozapine. Fatigue/sleepiness was mentioned most frequently - a side effect that apparently caused particular trouble to patients at the beginning of treatment: 'I was terribly sleepy upon taking the medication'. Besides patients felt muted, wornout, even dazed and numbed. As one patient complained: '... yes, it just dampens quite strongly ... yes, when the dosage was somewhat higher, I felt rather gooey'. About one-fifth of the respondents attributed the lack of motivation they felt to the treatment with clozapine. In most cases, the latter manifested itself in the patients' difficulty getting up in the morning: 'It is really difficult to get up then, to get out of bed ... which was easier for me before'. In addition, patients complained of passivity, lethargy, and a lack of enthusiasm and interest: '...yes, that I'm unmotivated ... before I got ill I read a lot and dealt with intellectual things, and today I don't do these things anymore... it's relatively rare that I still read something'. For a further fifth of the patients, hypersalivation was an aggravating concomitant of the medication: 'When I wake up, there's always this stain in my bed from slobbering'. However, according to one patient's view, this disadvantage is offset by clozapine's positive effect: 'It's true, I've got salivation through it, but at least it allows me to sleep for a few hours'. Every sixth respondent reported anticholinergic effects, in which constipation was the most frequent complaint ('you have to take laxatives with that stuff'). Similarly often, patients complained about weight gain: ' $\ldots$ and I mean, this is a point, of course, that isn't so nice with the medication, when you go swimming then somebody says: 'My God, have you become fat!' '... and you put on something like 10 kilos in 2 weeks, and then you get this tension in your belly, as if you were about to burst ...'. Another patient took it with a sense of humour: 'I don't really know how it functions ... but the people who take Clozaril like myself, they've all put on weight ... they've become corpulent ... but I'd rather be fat and clear-headed ...'. Every tenth respondent complained about orthostatic hypotension, above all about dizziness: 'Under that Clozaril, that I was given, I simply couldn't work... I stood on the ladder and then I got dizzy'. Just as frequently, cognitive deficits were cited as a negative consequence of clozapine medication. Here, it was particularly poor concentration which patients reported: '... yes, it's very difficult to concentrate, to focus on something ...'. The following negative effects of the medication were mentioned comparatively rarely - by a maximum $5 \%$ of the respondents: sexual dysfunction, increased perspiration, headaches, akathisia and, as put by the patients, a more general feeling of 'restlessness'.

\section{Risks of long-term treatment with clozapine}

When asked about the potential risks of longterm treatment with clozapine almost every third respondent did not know what to answer. Almost one patient in four denied that this drug may be accompanied by any risks. While one in ten was aware of the risk of damage to the haemotopoetic system: 'This change in the blood count cannot be precluded ... one doesn't really know ... the odd person gets it, and even if it is just with $1 \%$, that's bad enough'. Only one patient could spell out in more detail what kind of a change in the blood count might be caused by clozapine, but he was not too sure either: '... well, there's this thing with the ... with the leukocytes ... that's what you call them, isn't it?...that this is not such a good thing, perhaps...I mean, blood is among the most important things that man has, you see'. With the same frequency, patients expressed the fear of becoming addicted to the drug: 'Yes, I won't be able to live without these tablets anymore at all. I'm addicted to them, one could nearly say, yes, dependent on them'. Every tenth respondent 
anticipated the possibility that the treatment with psychotropic drugs might cause damage to inner organs, especially to the liver.

\section{Comparison of clozapine with traditional neuroleptic drugs}

As compared with conventional neuroleptics, patients clearly preferred clozapine (Table 2). Every second respondent criticized the extrapyramidal-motor side effects of the traditional neuroleptics, in particular haloperidol, or stressed their absence as an advantage of clozapine. Most frequently, patients described symptoms of parkinsonism: tremor ('I already had the shakes or something ... in the past ... but I don't get this anymore now...', 'rigidity (' ... these drugs totally destroy you ... make you unable to move and stiff all over... you can't speak anymore...this doesn't happen with Clozaril', or: 'I thought I was made out of concrete or something... I could hardly move when I took that stuff'; and akinesia ('Haloperidol was probably stronger... so that some things were ... when you moved, it felt like being a robot, that you're just totally slowed down and things, in walking, speaking, and in feeling'. One patient was infuriated about the side effects: "Let me tell you one thing: haloperidol is the last piece of shit ... you walk around like a robot, and I find it very doubtful that drugs like this are being prescribed at all ... I mean I would ban them immediately if I had the power to do that!'. On the other hand, the absence of akathisia is cited as an advantage of clozapine: 'With Clozaril ... you can sit still'. By contrast being on haloperidol was described as follows: 'I wasn't even able to sit down at the table and have my dinner. Yes, it's such a complete inner restlessness that keeps bothering you ... I never walked as much in my life as I did then'. Patients also had unpleasant memories of acute dystonia, which had occurred during treatment with conventional neuroleptics. As one patient reported: 'I was given haloperidol, and then I got eye cramps. I couldn't walk anymore, couldn't wash myself anymore, was unable to eat without assistance, couldn't speak anymore. I had throat cramps, too, and an awful lot of salivation. And when I came home from the hospital, they told me: "When you eat and drink like that you might as well have your dinner down in the cellar','

\section{Evaluation of clozapine 6 months after discharge from hospital}

As described in the method section, we reinterviewed a subsample of patients 6 months later. The evaluation of clozapine was virtually identical with the results at discharge from hospital. This applies to the positive and the negative effects as well as to the assessment of the possible risk of long-term treatment with this drug. Only patients' awareness of the risk that their condition might deteriorate when they stopped taking their medication was even more pronounced than previously $(55.3 \%$ as compared to $42 \cdot 1 \%$ ). The results of the comparison between clozapine and other neuroleptics, however, remained unchanged: patients clearly favoured clozapine.

\section{Comparison with the relatives' view}

As mentioned before, for 46 patients, interviews with their closest relatives were also available. In the following, we will point out differences between the two, which, using McNemar's test, reach statistical significance $(P<0 \cdot 05)$. If one compares the assessment of the positive effects by the relatives with that by the patients, no significant differences can be found. For both, the general improvement of the patients' condition and the calming effect were the most important desirable effects of clozapine treatment. There are obvious differences regarding patients' and relatives' judgements on the possible consequences of a discontinuation of taking the medication. Most strikingly, only one-third of the relatives did not know what would happen if patients stopped taking their medication, while it was nearly two-thirds of the patients who had no answer to this question. Most frequently, relatives expected a deterioration in the patients' condition. By contrast, only one-third of the patients feared such a development. The assessment of the negative effects of clozapine treatment revealed that weight gain was less frequently identified as a negative effect of clozapine by the patients than by their relatives. The opposite is true for those side effects, which are not directly visible, but may considerably affect patients' well-being and functioning: hypersalivation and the anticholinergic side effects (above all constipation and disturbance of accommodation) are the most frequently 
cited undesirable effects in this regard. The latter were hardly noticed by the relatives while they were frequently perceived as a problem by patients. The possibility of damage to inner organs was the most central concern of relatives with regard to the risks of clozapine treatment. Almost every third relative considered it as a possible consequence of taking the medication. By contrast, about every tenth patient was concerned about the risk of organ damage. Like the patients, the relatives also noted a number of advantages of clozapine over traditional neuroleptics. They also recognized that clozapine does not lead to extrapyramidal side effects - or does so to a lesser extent - which are known to occur in conjunction with traditional psychotropic drug treatment. Relatives further highlighted the reduction of inner unrest, that accompanied the older drugs, as an advantage of clozapine. Some relatives were also pleased with the fact that patients were less sedated than with previous medication. Further, the absence of akathisia and cognitive deficits with clozapine treatment were stressed as an improvement by the relatives.

\section{DISCUSSION}

The fact that patients, relatives and mental health professionals can differ considerably in their evaluation of the various positive and negative effects of clozapine treatment is perhaps the most important finding of our study. While psychiatrists prescribe the medication with the aim of reducing psychotic symptoms or preventing relapse, patients stressed the calming and relaxing effect as well as the improvement in sleep as a positive effect of clozapine. On the other hand, the drug's antipsychotic effect was mentioned comparatively rarely - which is all the more remarkable as the patients in this study had just experienced an exacerbation of their psychosis. One gets the impression that a significant proportion of the patients viewed clozapine more as a tranquilizer or a sleeping pill than an antipsychotic drug. This and the antidepressant effect reported by individual patients suggest that the medication's immediate effect may be most significant for how patients assess the drug. The - already achieved reduction of acute psychotic symptomatology and the prevention of relapse seem to be less important for the patients' view of clozapine.
While psychiatrists are aware of the risk of agranulocytosis and thus carry out regular white blood cell counts, the patients were not very aware of the risks associated with clozapine treatment. Only every tenth patient had a notion of the possible effects of clozapine on the haemopoetic system, a notion that was generally very vague. With the same frequency, patients expressed the fear that they might become dependent on clozapine. In Germany, as in many other countries, the provision of extensive and precise information to the patients about the risk of agranulocytosis is a special formal requirement for clozapine treatment. Moreover, patients are regularly reminded of that risk when they undergo frequent blood monitoring. Nevertheless, $90 \%$ did not mention it when interviewed in this study. One can only speculate about the reasons. Patients might deny a serious risk that is beyond their influence and avoid facing it. The risk may be very theoretical and despite all the medical information - difficult to understand. And a mere risk with a low probability of occurring might appear of little relevance in the light of many other more immediate real problems.

Differences are also evident between patients' and relatives' judgements on clozapine treatment. This is particularly true for the undesired effects, in which their visibility seems to play a major part. While patients more frequently complained of hypersalivation and anticholinergic side effects, which remain largely hidden from others, relatives more frequently were unhappy about the patients' apparent weight gain. In addition, relatives are even more aware than patients of the risk of relapse if clozapine medication is discontinued. On one issue, however, there is agreement between patients and relatives: both state the advantages of clozapine in comparison with conventional neuroleptics. There was unmistakable relief about the fact that patients are no longer plagued by the symptoms of parkinsonism, akathisia or acute dystonia. It is plausible to conclude that this positively affects compliance.

The results reported herein are of particular relevance for clinical practice. Our findings point to the necessity for psychiatrists to explore patients' subjective views and motivations with regard to their medication in order to improve treatment adherence. It may further be con- 
cluded that patient information and relative information should be specific and in some respects different. Appropriate information for patients should not be dominated by the agranulocytosis risk only, and may have to focus more on the antipsychotic effect. The potentially positive sedative effects are to be explicitly addressed. Discussions with relatives should especially address an adequate understanding of weight gain. Moreover, the range of views expressed within each group, i.e. patients and relatives, underlines the importance of a detailed assessment of individual concerns and perceived effects when addressing compliance issues.

With regard to the comparison between perceptions of clozapine and conventional neuroleptic drugs, our finding may be prone to a selection effect as those patients receiving this drug are likely to have found traditional neuroleptics unacceptable or of limited help. Through independent coding and multiple professional perspectives in the research team, it was attempted to minimize bias implicit in the analysis of qualitative data.

Based on a qualitative methodology, the present results are limited in terms of generalizability. However, the method was chosen for a specific purpose: the exploration of the subjective meanings patients associate with the treatment they receive. Knowledge of how patients - and relatives - think and speak about medication effects supplement the picture provided by clinical rating scales and may help to understand the motivations for compliance. In this regard, the present study can only be of an explorative nature. More detailed qualitative research is necessary for obtaining a more comprehensive and accurate understanding. On the other hand, our results could serve as the basis for developing a more standardized instrument to measure patients' and relatives' assessment of neuroleptic treatment.

This study is an example of how important subjective views, gathered using qualitative techniques may be quantified and subjected to statistical analysis. The method lends itself to more widespread use and could be incorporated into large scale outcome studies. In randomised controlled trials evaluating neuroleptic treatment regimes patients' and relatives' views might be assessed as outcome criteria in addition to using established quantitative scales. Frequencies of specific positive and negative statements about the treatments in question can be analysed, and differences between groups may be tested for statistical significance. This approach for capturing subjective outcome might be regarded as an alternative to conventional rating scales assessing patients' treatment satisfaction, self-rated side effects, and self-rated symptom change. Similar methods might also prove beneficial in evaluating patients' and relatives' views on types of psychiatric treatment other than atypical neuroleptics.

We thank the reviewers for their comments on an earlier draft of this paper.

\section{REFERENCES}

Angermeyer, M. C. \& Matschinger, H. (2000). Neuroleptika und Lebensqualität: Ergebnisse einer Patientenbefragung. (Neuroleptics and quality of life: results of a survey among schizophrenic patients). Psychiatrische Praxis 27, 64-68.

Baldessarini, R. J. \& Frankenburg, R. J. (1991). Clozapine: a novel antipsychotic agent. New England Journal of Medicine 324, 746-754.

Breier, A., Buchanan, R., Kirckpatrick, B., Davis, O., Irish, D., Summerfeldt, A. \& Carpenter, W. (1994). Effects of clozapine on positive and negative symptoms in outpatients with schizophrenia. American Journal of Psychiatry 151, 20-26.

Day, J. C., Bentall, R. P. \& Wagner, S. (1996). Schizophrenic patients' experiences of neuroleptic medication: a Q-methodologic investigation. Acta Psychiatrica Scandinavica 93, 397-402.

Finn, M. J., Bailey, M., Schultz, R. T. \& Faber, R. (1990). Subjective utility ratings of neuroleptics in treating schizophrenia. Psychological Medicine 35, 843-848.

Fitton, A. \& Heel, R. (1990). Clozapine: a review of its pharmacological properties and therapeutic use in schizophrenia. Drugs 40, 722-747.

Häfner, H., Riecher-Rössler, A., Maurer, K., Fätkenheuer, B. \& Löffler, W. (1992). First onset and early symptomatology of schizophrenia. European Archives of Psychiatry and Clinical Neuroscience 242, 109-118.

Holzinger, A., Müller, P., Priebe, S. \& Angermeyer, M. C. (2001). Die Ursachen der Schizophrenie aus der Sicht der Patienten. (The causes of schizophrenia as seen by the patients). Psychiatrische Praxis (in the press).

Kuckartz, U. (1988). Professionelle Version. Handbuch zum Textanalysesystem WinMax für Windows. (Professional version. Manual for the WinMax for Windows software package for the analysis of verbal data). Westdeutscher Verlag: Oplader.

Mayring, P. (1990). Qualitative Inhaltsanalyse. (Qualitative content analysis). Deutscher Studienverlag: Weinheim.

Meltzer, H. Y., Burnett, S., Bastani, B. \& Ramirez, L. (1990). Effects of six months of clozapine treatment on the quality of life of chronic schizophrenic patients. Hospital and Community Psychiatry 41, 892-897.

Meltzer, H., Cola, P., Way, L., Thompson, P., Bastani, B., Davies, M. \& Snitz, B. (1993). Cost-effectiveness of clozapine in neuroleptic-resistant schizophrenia. American Journal of Psychiatry 150, 1630-1638.

Merton, R. K. \& Kendall, P. C. (1945/46). The Focussed Interview. American Journal of Sociology 51, 541-557. 
Morris, S., Hogan, T. \& McGuire, A. (1998). The cost-effectiveness of clozapine - a survey of literature. Clinical Drug Investigation 15, 137-152.

Naber, D. (1995). A self rating to measure subjective effects of neuroleptic drugs, relationships to objective psychopathology, quality of life, compliance and other clinical variables. International Clinical Psychopharmacology 10 (suppl. 3), 133-138.

Retzow, A. \& Emrich, H. M. (1998). Therapie bipolarer affektiver Erkrankungen mit Valproat. (Treatment of bipolar affective disorders with valproate). Psychiatrische Praxis 25, 163-171.
Wagstaff, A. J. \& Bryson, H. M. (1995). Clozapine: a review of its pharmacological properties and therapeutic use in patients with schizophrenia who are unresponsive to or intolerant of classical antipsychotic agents. CNS Drugs 4, 370-400.

Windgassen, K. (1989). Schizophreniebehandlung aus der Sicht der Patienten. (Treatment of schizophrenia as seen by patients). Springer: Berlin.

Witzel, A. (1982). Verfahren der qualitativen Sozialforschung. Überblick und Alternativen. (Methods of qualitative social research. Overview and alternatives). Campus: Frankfurt. 